\section{Magnetic Crack-Detection}

Notes on Working Principles and Use of Apparatus. By G. B. Young. Pp. vii +60 . (London: Charles Griffin and Co., Ltd., 1942.) 2s. 6d. net.

$\mathrm{T}$ $\mathrm{HE}$ author states that this little book has been prepared at the request of friends in inspection departments to combine an outline of the working principles with the practical information needed in connexion with magnetic crack detection. In the light of this it is difficult to find justification for the historical notes which form the opening. On the other hand, the principles underlying this method of insfrection might, with great advantage, have been more fully and more clearly stated. The majority of its readers will have a very slight knowledge of the fundamental principles of magnetism, and probably none of their bearing on exceptional cases as represented by flawed material. Terms such as flux, field distortion, magnetic susceptibility will be almost meaningless to many, as the average examiner of crankshafts, gear-wheels, ball-races, etc., is by no means likely to have qualifications in magnetism. The discussion of different types of flaws with little, if any, reference to their influences on the magnetization of the body in which they occur may be regarded as extraneous, as the reader is, or should be, presumed to know them all already, while the man who is unfamiliar with this branch of inspection will find the information inadequate.

Halfway through the book, the author begins to open up his subject proper by giving practical directions on the methods of operating the machines in magnetizing and testing bars, slabs, disks and flat surfaces. For the testing of rings, the Johnson-Fel ring jig is recommended, but, though it is thus indicated as an accessory to the actual process of examination, not a word of description is devoted to it. There certainly will be found many practical hints or tips which would be most useful to the examiner who has learned to use the machines, and has already been trained in the subject of crack detection. Considering, however, the many possibilities of cracks or flaws being overlooked in consequence of mishandling the machine, say, by exceeding, or failing to reach the correct magnetic strength, one is bound to say that a more comprehensive view of the needs of the uninitiated reader should have been adopted.

\section{The Tropical Sky}

Maps of the Constellations visible in the latitudes of the West Indies, Guianas, Nigeria, E. Africa, Ceylon, Malaya, etc. $\left(5^{\circ}\right.$ to $10^{\circ} \mathrm{N}$. or thereabouts), and of the Planets and Solar System, showing how and where to Identify Them in their Starry Background. Compiled by H. E. Watson. Pp. $27+3$ maps. (Georgetown : Daily Chronicle, Ltd., 1942.) 3s. 6d. net.

$\mathrm{T}$ HE title of this work is a sufficient explanation of its scope; the maps will prove helpful to beginners who wish to learn the positions of the constellations and their principal stars, which are given up to magnitude 5. Separate charts are provided for finding the planets, and directions are supplied for making use of these charts at different periods.

A number of explanations are given of various astronomical matters, but unfortunately many of these are either inadequate or misleading. Some examples are selected and perhaps these will be rectified in a later edition. $\overrightarrow{\mathrm{P}} .8$ : It is incorrect to say that the Star of Bethlehem was a comet. There is no proof for this supposition. On the same page it is stated that meteors "are pulled down on to the earth if they approach us too closely". Meteors encounter the earth irrespective of our planet's attraction, which has very little to do with the cause of the encounter. P. 9: It is stated that the Milky Way contains some 3,000 million stars. The actual number is probably about thirty times this figure. P. 11: It is doubtful if an object glass $1 \frac{1}{2}-3$ in. in diameter, complete with brass cell, can be purchased for $15-30 s$. If such a price were paid one might suspect that the resulting telescope would not be achromatic. P. 13: It is not correct to say that Galileo was tortured until he recanted.

On Map 1 the constellation of Telescopium is printed as "Telescopum". M. D.

\section{Electrical Engineering Practice}

A Practical Treatise for Electrical, Civil and Mechanical Engineers. By J. W. Meares and R. E. Neale. Fifth edition, revised and enlarged. In 3 vols. Vol. 2. Pp. xii $+668+32$ plates. (London: Chapman and Hall, Ltd., 1942.) 35s, net.

THE previous edition of this book appeared in 1927 , and many changes in practice have taken place since that year, so that the new edition should prove welcome. The work is too well known to need detailed comment, and it is only necessary to remind readers that this particular volume is concerned with the transformation, conversion and storage of energy ; distribution and control in branch circuits; and applications of electrical energy. These main divisions include transformers, rotary convertors, rectifiers, electronic devices, secondary cells, circuits and systems of supply, circuit accessories and wiring systems, and, on the applicational side, lighting, heating, cooking, cooling, air-conditioning, and welding and cutting.

The book has been revised completely and new material has been added where deemed necessary. The basic conception remains as originally planned, and the work is useful alike to the student and the general engineer. In its new form the book should enjoy all the popularity of its predecessors.

\section{Electrical Technology for Telecommunications}

By W. H. Date. Pp. iv +160. (London, New York and Toronto: Longmans, Green and Co., Ltd., 1943.) 5s. net.

A $\mathrm{S}$ times change so the fundamental needs of A particular types of has had considerable experience in training electrical students for varied branches of applied electricity, and the war-time pressure on educationists to emphasize telecommunications, especially radio, must lead them to reconsider what in fundamental theory their students must know in view of the known work they are later to undertake. Without anticipating more specialized telecommunication work, the author has found space, by rejecting the direct-current machine and the associated technology, for whole chapters on inductance, capacitance, and transformers, and their reaction to alternating currents. As a first introduction to the subject the author is clear and comprehensive, at every step indicating examples of magnitudes and usage; the more subtle aspects of the subject do not, of course, appear.

L. E. C. Hughes. 